\title{
Valuing Innovative Endoscopic Techniques: Prophylactic Clip Closure After Endoscopic Resection of Large Colon Polyps
}

Eric D. Shah, MD, MBA ${ }^{1}$, Heiko Pohl, MD ${ }^{1,2}$, Douglas K. Rex, $\mathrm{MD}^{3}$, Michael B. Wallace, MD, $\mathrm{MPH}^{4}$, Seth D. Crockett, MD, MPH${ }^{5}$, Shannon J. Morales, MD ${ }^{1}$, Linda A. Feagins, MD ${ }^{6,7}$, Ryan Law, $\mathrm{DO}^{8}$

${ }^{1}$ Section of Gastroenterology and Hepatology, Dartmouth-Hitchcock Medical Center, Lebanon, NH

${ }^{2}$ Division of Gastroenterology, Department of Veterans Affairs, White River Junction, VT

${ }^{3}$ Division of Gastroenterology and Hepatology, Indiana University School of Medicine, Indianapolis, IN

${ }^{4}$ Division of Gastroenterology and Hepatology, Mayo Clinic, Jacksonville, FL

${ }^{5}$ Division of Gastroenterology and Hepatology, University of North Carolina School of Medicine, Chapel Hill, NC

${ }^{6}$ Division of Gastroenterology, The University of Texas at Austin Dell Medical School, Austin, TX

${ }^{7}$ VA North Texas Healthcare System, Dallas, Texas

${ }^{8}$ Division of Gastroenterology and Hepatology, University of Michigan, Ann Arbor, MI

SHORT TITLE: Budget impact analysis: clip closure after resecting large colon polyps

WORD COUNT: 2,354

ABSTRACT WORD COUNT: 248

\section{ADDRESS FOR CORRESPONDENCE:}

Ryan Law, DO

Michigan Medicine Division of Gastroenterology and Hepatology

1500 E Medical Center Drive

3912 Taubman Center SPC 5362

Ann Arbor, MI 48109

AUTHOR CONTRIBUTIONS: Dr. Shah designed the study, performed literature review and data extraction, and analyzed data. Drs. Shah, Law, and Pohl conceived the study and drafted the manuscript. All authors interpreted the data, critically revised the manuscript, and approved the final copy.

ACKNOWLEDGEMENTS: Large Polyp Study Group Collaborators: Ian S. Grimm, Matthew T. Moyer, Muhammad K. Hasan, Douglas Pleskow, B. Joseph Elmunzer, Mouen A. Khashab, Omid Sanaei, Firas H. Al-Kawas, Stuart R. Gordon, Abraham Mathew, John M. Levenick, Harry R. Aslanian, Fadi Antaki, Daniel von Renteln, Amit Rastogi, Jeffrey A. Gill, Maria Pellise

CONFLICTS OF INTEREST: Dr. Shah is supported by the 2019 AGA-Shire Research Scholar Award in Functional GI and Motility Disorders. Dr. Feagins was supported by VA MERIT CX000815. Dr. Law was a consultant for Olympus America and received royalties from UpToDate. Dr. Rex was a consultant for Olympus Corporation, Boston Scientific, Medtronic, Aries, Braintree Laboratories; research support: EndoAid, Olympus Corporation, Medivators, Erbe USA; ownership: Satisfai Health. Dr. Pohl received research grants from Boston Scientific, US Endoscopy, and Aries Pharmaceuticals. Dr. Wallace consulted for Virgo Inc, Cosmo/Aries Pharmaceuticals, Anx Robotica, Covidien; obtained research grants from: Fujifilm, Boston Scientific, Olympus, Medtronic, Ninepoint Medical, Cosmo/Aries Pharmaceuticals; held stock options in Virgo, Inc.; consulted on behalf of Mayo Clinic for GI Supply (2018), Endokey, Endostart, Boston Scientific; received general payments/minor food and beverage from: Synergy Pharmaceuticals, Boston Scientific, Cook Medical. The other authors have no relevant disclosures.

This is the author's manuscript of the article published in final edited form as:

Shah, E. D., Pohl, H., Rex, D. K., Wallace, M. B., Crockett, S. D., Morales, S. J., .. \& Law, R. (2020). Valuing Innovative Endoscopic Techniques: Prophylactic Clip Closure After Endoscopic Resection of Large Colon Polyps. Gastrointestinal Endoscopy. https://doi.org/10.1016/j.gie.2020.01.018 


\section{ABSTRACT}

BACKGROUND AND AIMS: Clip closure of the mucosal defect after resecting large $(\geq 20$ $\mathrm{mm}$ ) nonpedunculated colorectal polyps reduces postprocedure bleeding and is cost-saving to payers. Clip costs are not reimbursed by payers, posing a major barrier to adoption of this technique in the community. We aimed to determine appropriate clip costs to support broader use of this procedure in practice.

METHODS: We performed budget impact analysis using our recent decision analytic model, comparing prophylactic clip closure to no clip closure on national cost and outcomes data, to determine the maximum feasible clip price while maintaining cost-savings in practice. Sensitivity analyses were performed on important clinical factors.

RESULTS: In the original model, the baseline postprocedure bleeding risk was $6.8 \%$, increasing cost-of-care by $\$ 614.11$ averaged among all patients undergoing large polyp resection without clip closure. Prophylactic clip closure of only large right-sided polyps reduced postprocedure bleeding risk by $70.7 \%$ but resulted in cost-saving only if price of clips was $\$ 100$ or less. Comparatively, prophylactic clip closure of large left-sided polyps had no clinical benefit and was not cost-saving. Clip closure strategies focused on only extra-large polyps ( $\geq 40 \mathrm{~mm}$ ), or patients taking antithrombotics regardless of polyp characteristics, were only minimally costsaving. Cost-savings and maximum tolerated clip prices depended on medical comorbidity, which directly influences the costs-of-care to manage postprocedure bleeding.

CONCLUSIONS: Prophylactic clip closure after endoscopic resection of large colon polyps, particular those in the right colon segment, is cost-saving, but requires clip costs less than $\$ 100$. Translating these findings into practice requires gastroenterology practices to obtain 
reimbursement from payers for improved clinical outcomes and to align commercial clip prices with this clinical indication.

KEYWORDS: hemoclip, endoclip, endoscopic mucosal resection, postpolypectomy bleeding, cost effectiveness analysis, value

\section{INTRODUCTION}

Endoscopic management of large colon polyps ( $\geq 20 \mathrm{~mm}$ in diameter) is increasingly preferred over surgery as endoscopic mucosal resection has matured as a skill offered in many gastroenterology practices ${ }^{1-5}$. However, postprocedure bleeding, which may require additional evaluation and treatment, remains the most likely adverse event after endoscopic resection ${ }^{6}$. Three randomized controlled trials published earlier this year found that prophylactic endoclip closure of a resection bed can reduce bleeding risk after endoscopic resection of large right-sided polyps $^{7-9}$. We recently reported that prophylactic clip closure delivered in a programmatic fashion would save $\$ 422.98$ to Medicare for every patient undergoing large right-sided polyp resection, due to lower risks and costs to manage postprocedure bleeding. Despite clear evidence of clinical efficacy and cost-savings, the financial pressures on gastroenterology practices of routinely placing clips after large polyp resection will likely remain a major challenge to broad adoption of this practice.

When existing endoscopic technology is re-tooled for a new clinical purpose,

reimbursement is the usual failure point to adoption. ${ }^{10}$ Reimbursement for endoscopic equipment requires alignment between costs and benefits among payers, practices, and industry. In usual fee-for-service arrangements, benefits and costs of prophylactic clipping are misaligned. The commercial individual endoclip prices vary between $\$ 150$ to $\$ 200$ depending on the 
manufacturer $^{11}$, a price likely set according to the traditional use of endoclips in achieving hemostasis in which a single endoclip is often sufficient ${ }^{12}$. In contrast, complete clip closure after resecting a large colon polyp can require several clips, adding substantial cost to the management of each large polyp resection whereas payer reimbursement to gastroenterology practices remains unchanged.

Thankfully, modern alternative reimbursement pathways can enable practices to incorporate clip closure into routine practice. ${ }^{13}$ Managed care systems, who both (1) insure patients against health risks and (2) provide gastroenterology care, are ideally situated to directly negotiate clip costs which offset postprocedure bleeding costs. Other gastroenterology group practices can negotiate with individual payers for additional payment using appropriate modifiers (such as modifier-22) to cover equipment costs associated with delivering specialized services to patients. Group practices can also consider engaging in professional services agreements with hospitals either as part of clinically integrated networks (CIN) to reduce postprocedural hospitalization rates, or in the care of patients who are enrolled in accountable care organizations (ACOs). However, all of these pathways require evidence to link appropriate clip prices to costsavings associated with improved patient outcomes.

Using budget impact analysis and threshold pricing techniques, we aimed to determine the optimal clip price to support gastroenterology practices, payers, and industry toward implementing routine prophylactic clip closure after resecting large polyps in usual care.

\section{METHODS}


Recognizing the clinical urgency toward reducing postprocedure bleeding for patients undergoing endoscopic large polyp resection through routine prophylactic clip closure, we recently reported a brief communication on our development of a decision-analytic model which found cost-savings to payers associated with routine prophylactic clip closure of an endoscopic resection site from a large $(\geq 20 \mathrm{~mm})$ colon polyp ${ }^{14}$. Model inputs were derived using a systematic review to identify relevant postprocedure bleeding rates and technical aspects of performing clip closure in clinical trials. The full methodology for this model is reported separately ${ }^{14}$. The average cost of one bleeding event was $\$ 6,458.05$ for a 65 -year-old patient with at least one medical comorbidity, based on demographics of individuals with large colon polyps in clinical trials.

In defining the maximum possible clip price, we assumed that payers could transfer their full cost-savings through alternative reimbursement pathways to gastroenterology practices who would use those cost-savings to purchase clips.

\section{Programmatic clinical strategies for appropriate clip closure indications}

We evaluated the potential cost-savings associated with several reasonable routine clinical strategies for prophylactic clip closure in practice based on patient- and polyp-specific factors identified in recent clinical trials: (1) closure of all large colon polyps, (2) closure of right-sided polyps only, (3) closure of left-sided polyps only, (4) closure of extra-large polyps only ( $\geq 40 \mathrm{~mm}$ ) regardless of location, or (5) closure of all large polyp resection sites ( $\geq 20 \mathrm{~mm}$ ) regardless of location in patients on antithrombotic medications that are held following ASGE guidelines $^{15}$. 


\section{Analysis}

The maximum tolerated commercial clip price was determined using threshold analysis. Threshold analysis is a technique used in cost modeling to solve for a missing variable, such that net cost-savings would be zero. To accomplish this, we set (cost-savings from reduced hospitalization costs due to postprocedure bleeding $)=($ threshold clip price $) \times($ the distribution of the number of clips required to achieve complete clip closure in clinical trials: median of 4 clips; range of 1 to 8 clips). ${ }^{7,8,16}$ Overall, this design assumed that cost-savings would be passed from payers to gastroenterology practices and industry through alternative reimbursement pathways.

Probabilistic sensitivity analysis was performed from a gastroenterology practice perspective using 10,000 simulations of the model to assess the probability that routine prophylactic clip closure would achieve cost-savings at different clip pricing levels.

Sensitivity analyses were performed to evaluate how model inputs influenced potential cost-savings with prophylactic clip closure for each clinical strategy for routine prophylactic clip closure. We also conducted analyses on how the presence of a major medical comorbidity, or no comorbidity, would affect cost-savings, using specific definitions of medical comorbidity (known as MC in coding) and major medical comorbidity (known as MMC in coding) outlined in the 2019 Centers for Medicare \& Medicaid Services (CMS) Final Rule for the Acute Inpatient Prospective Payment System ${ }^{26}$ which directly impacts hospital reimbursements for postprocedure bleeding management.

\section{RESULTS}

In our original study, we found a baseline $7.0 \%$ risk of postprocedure bleeding after resection of a large colon polyp (95\% confidence interval $[\mathrm{CI}]=4.9-9.7 \%$ ) based on 2 randomized 
clinical trials enrolling 899 patients, resulting in $\$ 453.44$ excess cost for every patient undergoing polypectomy to cover the risk of postprocedure bleeding. Polyp location was the most important factor in that study. The bleeding risk after resection of right-sided colon polyps proximal to or including the hepatic flexure was $9.5 \%$ (95\% CI, 6.6\%-13.2\%) and $\$ 614.11$ excess cost for these patients, compared to a $1.4 \%$ (95\% CI, $0.0 \%-4.9 \%)$ bleeding risk after resection of left-sided polyps.

\section{Threshold clip prices}

Costs with and without routine prophylactic clip closure and cost-savings to payers are reported in Table 1 for each programmatic clinical strategy. Maximum clip prices based on these cost-savings are reported in Table 2 for each programmatic clinical strategy. Assuming a median number of 4 clips were needed to achieve complete clip closure based on 2 recent RCTs, cost savings with routine clip closure after EMR of a large right-sided polyp would require a maximum commercial clip price no more than $\$ 100$ (Figure 1). Routine clip closure after EMR of a large left-sided polyp was not cost-saving, so maximum tolerated clip prices were not determined. Cost-savings (and lower maximum tolerated clip prices) were lower among patients with no medical comorbidities, due to lower costs to manage postprocedure bleeding in these patients. Alternative routine clip closure strategies focused on extra-large polyps $\geq 40 \mathrm{~mm}$ in size regardless of location, or routine clip closure only after EMR of all large polyps $\geq 20 \mathrm{~mm}$ in patients on antithrombotics, resulted in $62.9 \%$ and $69.2 \%$ respective risk reductions in postprocedure bleeding; however, the absolute decrease in risk was small. Thus, current commercial clip prices did not support cost-savings for routine prophylactic clip closure with 
these strategies, which necessitated clip prices no greater than $\$ 11$ to $\$ 21$ per clip to achieve cost-savings in practice.

In addition to polyp location, cost-savings and maximum tolerated clip prices were also dependent on medical comorbidities. Patients with major medical comorbidities, as defined by CMS, necessitated higher reimbursements for management of postprocedure bleeding, had higher potential cost-savings and higher tolerated clip prices with routine prophylactic clip closure.

Likelihood of cost-savings to gastroenterology practices with prophylactic clip closure depends on clip price

We modeled the likelihood of cost-savings at various clip prices, based on the clinical strategy for routine prophylactic clip closure (Figure 2). Routine clip closure after right-sided polypectomy was the only clinical strategy which was cost-saving at a clip price of $\$ 50$. Above \$75 per clip, no clinical strategy for routine prophylactic clip closure resulted in cost-savings more than $50 \%$ of the time.

\section{Sensitivity analysis on model inputs}

The preference for each clinical clip closure strategy based on whether cost-savings is achieved is shown in Figure 3, varied by cost of postprocedure bleeding, theoretical clip price, and technical success of achieving complete clip closure. Clip closure after EMR of right-sided polyps was increasingly preferred for patients with a greater number of medical comorbidities, represented by increasing costs to manage postprocedure bleeding (left pane). Higher technical success of the endoscopist in achieving complete clip closure did not influence cost-savings 
preference toward clip closure or maximum tolerated clip prices. Clip closure among patients on antithrombotics, as well as clip closure in the left colon segment, were not preferred clinical strategies regardless of the cost to manage postprocedure bleeding.

\section{DISCUSSION}

We used budget impact and threshold pricing techniques to determine the maximum tolerated pricing for endoclips to support routine prophylactic clip closure after resecting large colon polyps. We found that clip prices less than $\$ 100$ would be needed to support routine clip closure of large right-sided polyps, recognizing that in reality even this price may need to be shared among 3 stakeholders: payers, GI practices, and industry. Routine clip closure of leftsided polyps would not decrease postprocedure bleeding rates and was not cost-saving. Prophylactic clip closure strategies focused on only extra-large polyps $\geq 40 \mathrm{~mm}$ in size regardless of location, or routine clip closure only after EMR of all large polyps $\geq 20 \mathrm{~mm}$ in patients on antithrombotics, would require marked reduction in clip price to achieve cost-savings to gastroenterology practices.

Reimbursement is often the major barrier to broad adoption of promising advanced endoscopic techniques, especially when these techniques use known endoscopic technologies. ${ }^{17,18}$ This is especially disconcerting when clinical outcomes with such techniques are apparent, the technology is well known, and the technology is readily available in most endoscopy centers. Payers usually reimburse gastroenterology practices for endoscopic procedures under a fixed fee-for-service model, using a global service code intended to cover the costs of equipment, personnel including sedation staff, and facilities. ${ }^{19}$ To offer the appropriate endoscopic care (and to avoid morbidities associated with surgery to the patient), ${ }^{20}$ 
gastroenterology practices must be able to absorb the additional costs within a fixed fee-forservice budget. Supporting routine prophylactic clip closure financially would require payers to either (1) transfer cost-savings to gastroenterology practices from through one of several contemporary alternative reimbursement pathways or (2) improve reimbursement through traditional fee-for-service mechanisms. Furthermore, clip prices would need to realigned with this clinical use.

There are likely other potential hidden financial benefits beyond reducing postprocedure bleeding by enabling reimbursement for endoscopic clip placement, to the extent that cases are shifted to endoscopy from surgery. As an example, there were 3 delayed perforations in the nonclipped arm in contrast to no delayed perforations in the clipped arm of Pohl et $\mathrm{al}^{7}$. The result of these factors is that endoscopists may be willing to undertake endoscopic resection because of decreased fear of adverse events.

Endoscopic clips remain the most widely used and widely studied modality to prevent postprocedure bleeding after endoscopic resection of complex colorectal polyps; however, complete closure of large or irregularly shaped defects may not be feasible in some patients, which is certainly a limitation of this approach. Alternative etiologies to prevent postprocedure bleeding exist but remain less well studied. Conceptually, over-the-scope (OTS) clipping devices could be used to close postresection defects although published data are nonexistent. Furthermore, OTS clips are costly and not available at many institutions. There are limited, but promising, data describing the use of a novel biocompatible synthetic extracellular matrix (Purastat, 3D Matrix, Waltham, Mass, USA) that can be applied to the resection defect to prevent delayed bleeding. ${ }^{21}$ This self-assembling microstructure is delivered in a soluble form with conversion to a hydrogel matrix upon luminal contact with a goal to promote tissue regeneration. 
Another approach involves endoscopic suturing to close the resection site. ${ }^{22}$ The most promising approach to prevention of postprocedure bleeding after mucosal resection is the development of cold snare EMR. ${ }^{23}$ This technique mirrors conventional EMR in every way except that tissue is resected using mechanical force in lieu of electrocautery. The tenets of this technique lie in the supposition that most postprocedure adverse events (ie, bleeding, perforation) are related to electrocautery injuries. A recent systematic review of case-series data found complete resection rates of $99.3 \%$ with no perforations or postprocedure bleeding events. ${ }^{24}$ Although this approach is promising, further evaluation is desperately needed to determine its role in resection of complex colon polyps.

There are several important considerations regarding application of these findings in practice. First, our proposed clip prices are threshold prices that assume full transfer of costsavings from lower hospitalization rates for postprocedure bleeding toward purchasing endoclips. In reality, gastroenterology practices should also consider how adding clip closure to their practice would impact their personnel costs and other endoscopic/anesthesia equipment costs, factors which would may lower the maximum tolerated clip price. Practices should also consider their local payer mix and geographic variation in reimbursement because even Medicare reimbursement varies by specific rural and geographic multipliers compared with the national average Medicare reimbursement reported in our present analysis. Because the aim of the endoscopist in underlying trials was to achieve complete clip closure, our findings cannot support any alternative clinical protocol (such as routine incomplete closure) in achieving the potential bleeding risk reductions or cost-savings reported here. Finally, it is important to recognize that this analysis is intended solely to support dissemination of this clinically effective technique supported by recent clinical trials. 
In this study, we used budget impact and threshold pricing techniques to determine the maximum tolerated clip prices to enable routine prophylactic clip closure after resection of large colon polyps. The study strengths include adherence to methodologic guidelines, inclusion of both payer and gastroenterology practice perspectives on whom expected cost-savings might have the greatest potential influence, and the use of national reimbursement data and common reimbursement codes to improve generalizability of our study findings. Our study determined that prophylactic clip closure strategy after resection of large right-sided nonpedunculated colon polyps is the optimal cost-saving strategy but requires clip costs $<\$ 100$. These findings provide a model for gastroenterology practices to pursue alternative reimbursement means and appropriate endoclip acquisition to support prophylactic clip closure as a clinically effective and innovative technique in routine practice.

\section{REFERENCES}

1. Grimm I, Peery AF, Kaltenbach T, Crockett SD. Quality Matters: Improving the Quality of Care for Patients With Complex Colorectal Polyps. Am J Gastroenterol. 2018;113:317-21.

2. Jayanna M, Burgess NG, Singh R, Hourigan LF, Brown GJ, Zanati SA, et al. Cost Analysis of Endoscopic Mucosal Resection vs Surgery for Large Laterally Spreading Colorectal Lesions. Clin Gastroenterol Hepatol. 2016;14:271-278.e2.

3. Hassan C, Repici A, Sharma P, Correale L, Zullo A, Bretthauer M, et al. Efficacy and safety of endoscopic resection of large colorectal polyps: a systematic review and metaanalysis. Gut. 2016;65:806-20.

4. Saunders BP, Tsiamoulos ZP. Endoscopic mucosal resection and endoscopic submucosal dissection of large colonic polyps. Nat Rev Gastroenterol Hepatol. 2016;13:486-96.

5. Law R, Das A, Gregory D, Komanduri S, Muthusamy R, Rastogi A, et al. Endoscopic resection is cost-effective compared with laparoscopic resection in the management of complex colon polyps: an economic analysis. Gastrointest Endosc. 2016;83:1248-57.

6. Burgess NG, Metz AJ, Williams SJ, Singh R, Tam W, Hourigan LF, et al. Risk Factors for Intraprocedural and Clinically Significant Delayed Bleeding After Wide-field Endoscopic Mucosal Resection of Large Colonic Lesions. Clin Gastroenterol Hepatol. 2014;12:651661.e3. 
7. Pohl H, Grimm IS, Moyer MT, Hasan MK, Pleskow D, Elmunzer BJ, et al. Clip Closure Prevents Bleeding After Endoscopic Resection of Large Colon Polyps in a Randomized Trial. Gastroenterology. 2019 Mar 15;

8. Feagins LA, Smith AD, Kim D, Halai A, Duttala S, Chebaa B, et al. Efficacy of Prophylactic Hemoclips in Prevention of Delayed Post-Polypectomy Bleeding in Patients with Large Colonic Polyps. Gastroenterology [Internet]. 2019 May [cited 2019 Jul 30]; Available from: https://linkinghub.elsevier.com/retrieve/pii/S0016508519408597

9. Albéniz E, Álvarez MA, Espinós JC, Nogales O, Guarner C, Alonso P, et al. Clip Closure After Resection of Large Colorectal Lesions With Substantial Risk of Bleeding. Gastroenterology [Internet]. 2019 Jul [cited 2019 Aug 13]; Available from: https://linkinghub.elsevier.com/retrieve/pii/S0016508519411347

10. Shah ED, Hosmer AE, Patel A, Morales S, Law R. Valuing innovative endoscopic techniques: endoscopic suturing to prevent stent migration for benign esophageal disease. Gastrointest Endosc. 2019 Aug 23;

11. Parikh ND, Zanocco K, Keswani RN, Gawron AJ. A Cost-efficacy Decision Analysis of Prophylactic Clip Placement After Endoscopic Removal of Large Polyps. Clin Gastroenterol Hepatol. 2013;11:1319-24.

12. Binmoeller KF, Thonke F, Soehendra N. Endoscopic hemoclip treatment for gastrointestinal bleeding. Endoscopy. 1993;25:167-70.

13. Muthusamy VR, Komanduri S. Innovating in Your Practice: Overcoming Barriers to Create New Opportunities. Clin Gastroenterol Hepatol. 2019;17:580-3.

14. Shah ED, Pohl H, Rex DK, Morales SJ, Feagins LA, Law R. Routine Prophylactic Clip Closure is Cost Saving After Endoscopic Resection of Large Colon Polyps in a Medicare Population. Gastroenterology [Internet]. 2019 Nov [cited 2019 Nov 16]; Available from: https://linkinghub.elsevier.com/retrieve/pii/S0016508519415618

15. Acosta RD, Abraham NS, Chandrasekhara V, Chathadi KV, Early DS, Eloubeidi MA, et al. The management of antithrombotic agents for patients undergoing GI endoscopy. Gastrointest Endosc. 2016;83:3-16.

16. Liaquat H, Rohn E, Rex DK. Prophylactic clip closure reduced the risk of delayed postpolypectomy hemorrhage: experience in 277 clipped large sessile or flat colorectal lesions and 247 control lesions. Gastrointest Endosc. 2013;77:401-7.

17. Grimm IS, Kroch DA, Brill JV. Reimbursement for endoscopic innovations: the final hurdle. Gastrointest Endosc. 2019;89:274-6.

18. Shah ED, Chang AC, Law R. Valuing innovative endoscopic techniques: per-oral endoscopic myotomy for the management of achalasia. Gastrointest Endosc [Internet]. 2018 Apr [cited 2018 Nov 18]; Available from: https://linkinghub.elsevier.com/retrieve/pii/S0016510718326166 
19. Dorn SD. The Road Ahead 3.0: Changing Payments, Changing Practice. Clin Gastroenterol Hepatol. 2016;14:785-9.

20. Keswani RN, Law R, Ciolino JD, Lo AA, Gluskin AB, Bentrem DJ, et al. Adverse events after surgery for nonmalignant colon polyps are common and associated with increased length of stay and costs. Gastrointest Endosc. 2016;84:296-303.e1.

21. Subramaniam S, Kandiah K, Thayalasekaran S, Longcroft-Wheaton G, Bhandari P. Haemostasis and prevention of bleeding related to ER: The role of a novel self-assembling peptide. United Eur Gastroenterol J. 2019;7:155-62.

22. Kukreja K, Chennubhotla S, Bhandari B, Arora A, Singhal S. Closing the Gaps: Endoscopic Suturing for Large Submucosal and Full-Thickness Defects. Clin Endosc. 2018;51:352-6.

23. Piraka C, Saeed A, Waljee AK, Pillai A, Stidham R, Elmunzer BJ. Cold snare polypectomy for non-pedunculated colon polyps greater than $1 \mathrm{~cm}$. Endosc Int Open. 2017;5:E184-9.

24. Thoguluva Chandrasekar V, Spadaccini M, Aziz M, Maselli R, Hassan S, Fuccio L, et al. Cold snare endoscopic resection of nonpedunculated colorectal polyps larger than $10 \mathrm{~mm}$ : a systematic review and pooled-analysis. Gastrointest Endosc. 2019;89:929-936.e3.

25. 2019 Final Rule for the Acute Inpatient Prospective Payment System. https://www.cms.gov/Medicare/Medicare-Fee-for-ServicePayment/AcuteInpatientPPS/FY2019-IPPS-Final-Rule-Home-Page-Items/FY2019-IPPSFinal-Rule-Tables.html. Cent Medicare Medicaid Serv. 


\section{FIGURE LEGENDS}

Figure 1: Maximum commercial clip prices to enable routine prophylactic clip closure. These prices assume that payers could pass cost-savings from reduced hospitalization costs to manage postprocedure bleeding to gastroenterology practices.

Figure 2: Probability of achieving cost-savings with routine prophylactic clip closure depends on clip price. At clip prices greater than $\$ 100$, the probability of cost-savings was less than $50 \%$ regardless of clip closure strategy.

Figure 3: Preference toward routine prophylactic clip closure are impacted by the choice of clinical strategy, cost of postprocedure bleeding, and clip price, but not technical success of achieving complete clip closure. 
Table 1: Average added cost of a bleeding event per patient among all patients undergoing endoscopic resection of a large $(\geq 20$ mm) nonpedunculated polyp with and without clipping of the mucosal defect. Shown are costs and cost-savings to payers with several possible routine clip closure strategies. The highest cost-savings were found for prophylactic clip closure after resecting large nonpedunculated polyps in the right colon segment. Cost-savings were higher if clip closure was performed among individuals with greater medical comorbidity. Base-case is highlighted in bold.

\begin{tabular}{|c|c|c|c|c|}
\hline Strategy & Medical comorbidities & $\begin{array}{l}\text { Average cost of } \\
\text { bleeding event without } \\
\text { clip closure } \\
\text { (Column A) }\end{array}$ & $\begin{array}{l}\text { Average cost of } \\
\text { bleeding event with clip } \\
\text { closure } \\
\text { (Column B) }\end{array}$ & $\begin{array}{l}\text { Cost-savings } \\
\text { (Column A minus B) }\end{array}$ \\
\hline \multirow{3}{*}{$\begin{array}{l}\text { All large colon polyps }(\geq 20 \\
\text { mm) }\end{array}$} & None & $\$ 319.80$ & $\$ 116.79$ & $\$ 203.01$ \\
\hline & 1+ comorbidity & $\$ 453.44$ & $\$ 165.59$ & $\$ 287.85$ \\
\hline & $1+$ major comorbidity & $\$ 769.98$ & $\$ 281.19$ & $\$ 488.79$ \\
\hline \multirow[t]{3}{*}{ Right colon segment only* } & None & $\$ 433.12$ & $\$ 126.96$ & $\$ 306.16$ \\
\hline & 1+ comorbidity & $\$ 614.11$ & $\$ 180.02$ & $\$ 422.98$ \\
\hline & 1+ major comorbidity & $\$ 1,042.82$ & $\$ 305.68$ & $\$ 737.14$ \\
\hline \multirow[t]{3}{*}{ Left colon segment only** } & None & $\$ 62.39$ & $\$ 96.23$ & $-\$ 33.84$ \\
\hline & 1+ comorbidity & $\$ 88.47$ & $\$ 136.44$ & $-\$ 47.97$ \\
\hline & $1+$ major comorbidity & $\$ 150.23$ & $\$ 231.69$ & $-\$ 81.46$ \\
\hline \multirow{3}{*}{$\begin{array}{l}\text { All extra-large colon polyps } \\
(\geq 40 \mathrm{~mm})\end{array}$} & None & $\$ 253.04$ & $\$ 160.47$ & $\$ 92.57$ \\
\hline & 1+ comorbidity & $\$ 358.78$ & $\$ 227.52$ & $\$ 131.26$ \\
\hline & $1+$ major comorbidity & $\$ 609.25$ & $\$ 386.35$ & $\$ 222.90$ \\
\hline \multirow{3}{*}{$\begin{array}{l}\text { All large colon polyps in } \\
\text { patients on antithrombotic } \\
\text { medications }\end{array}$} & None & $\$ 182.19$ & $\$ 133.23$ & $\$ 48.96$ \\
\hline & 1+ comorbidity & $\$ 258.32$ & $\$ 188.91$ & $\$ 69.41$ \\
\hline & 1+ major comorbidity & $\$ 438.66$ & $\$ 320.79$ & $\$ 117.87$ \\
\hline
\end{tabular}

Costs are averaged among all patients undergoing polypectomy, accounting for the differential bleeding risk based on whether prophylactic clip closure is performed. *Hepatic flexure, ascending colon, cecum. **Transverse colon to rectum. 
Table 2. Maximum clip price to achieve cost-savings in performing prophylactic clip closure.

\begin{tabular}{|l|l|l|l|}
\hline \multirow{2}{*}{ Clipping Strategy } & \multicolumn{2}{|c|}{ Maximum clip price by medical comorbidities for a patient undergoing polypectomy } \\
\cline { 2 - 4 } & No medical comorbidities & $\begin{array}{l}\text { At least one medical } \\
\text { comorbidity (base case) }\end{array}$ & $\begin{array}{l}\text { At least one major medical } \\
\text { comorbidity }\end{array}$ \\
\hline All large colon polyps $(\mathbf{2 0 m m})$ & $\$ 46.85$ & $\mathbf{\$ 6 6 . 4 3}$ & $\$ 112.80$ \\
\hline Right colon segment only* & $\$ 70.65$ & $\mathbf{\$ 1 0 0 . 1 8}$ & $\$ 170.11$ \\
\hline Left colon segment only** & Not cost-saving & Not cost-saving & Not cost-saving \\
\hline $\begin{array}{l}\text { All extra-large colon polyps }(\geq \mathbf{4 0} \\
\text { mm) }\end{array}$ & $\$ 21.36$ & $\mathbf{\$ 3 0 . 2 9}$ & $\$ 51.44$ \\
\hline $\begin{array}{l}\text { All large colon polyps in patients } \\
\text { on antithrombotic medications }\end{array}$ & $\$ 11.30$ & $\mathbf{\$ 1 6 . 0 2}$ & $\$ 27.20$ \\
\hline
\end{tabular}

Patients with increasing medical comorbidities experience higher costs-of-care to manage postprocedure bleeding, resulting in higher maximum clip prices for these patients while maintaining cost-savings. Medical comorbidities and major medical comorbidities are defined by the 2019 Centers for Medicare \& Medicaid Services (CMS) Final Rule for the Acute Inpatient Prospective Payment System $^{25}$, because these definitions specifically impact cost-savings. *Hepatic flexure, ascending colon, cecum. **Transverse colon to rectum. 


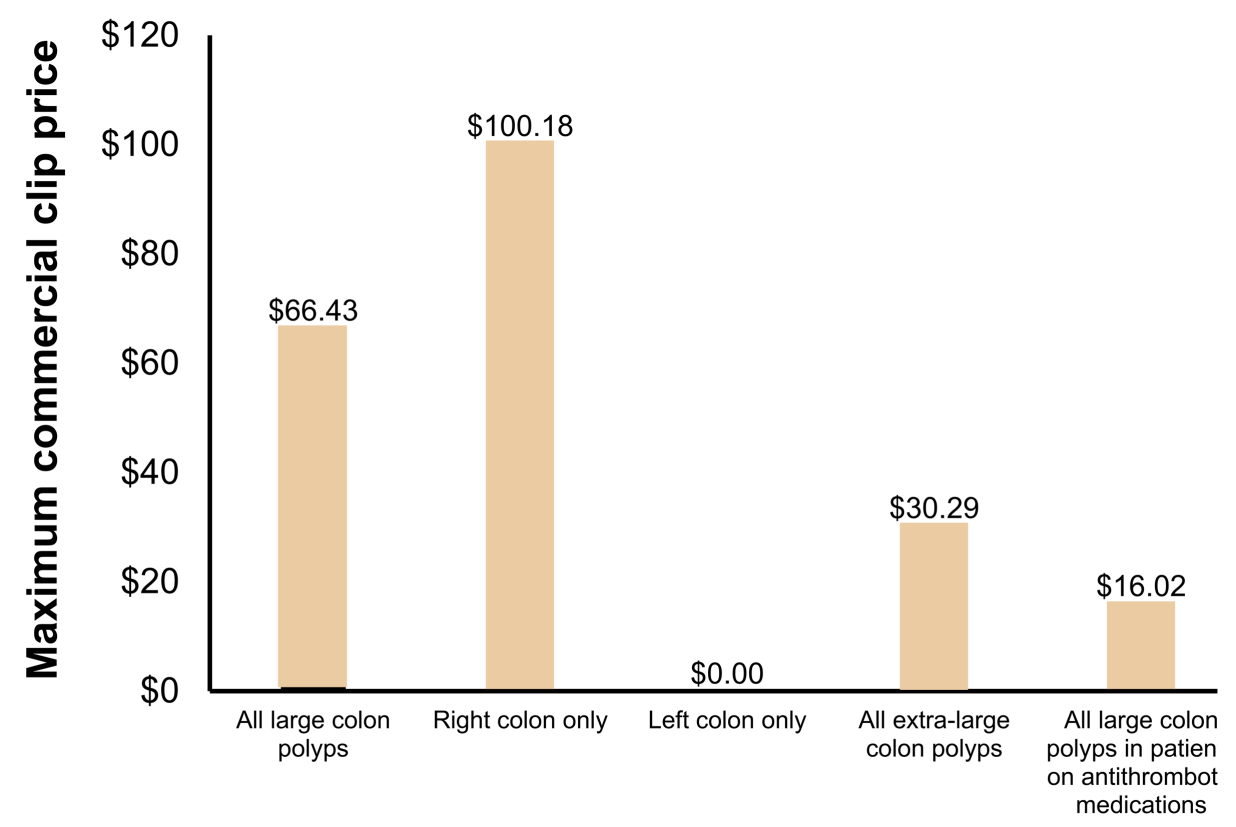




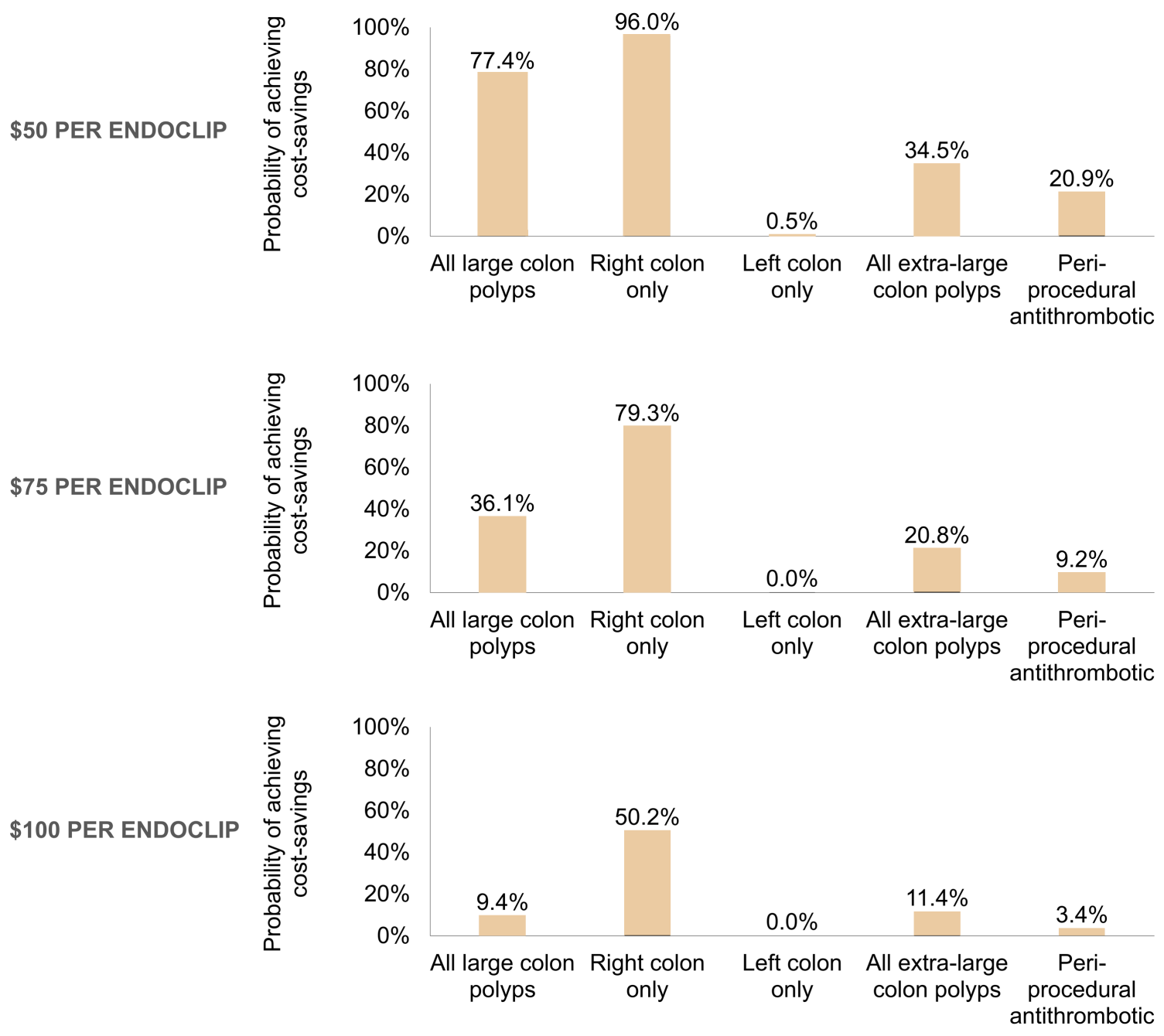




\section{Clipping strategy}

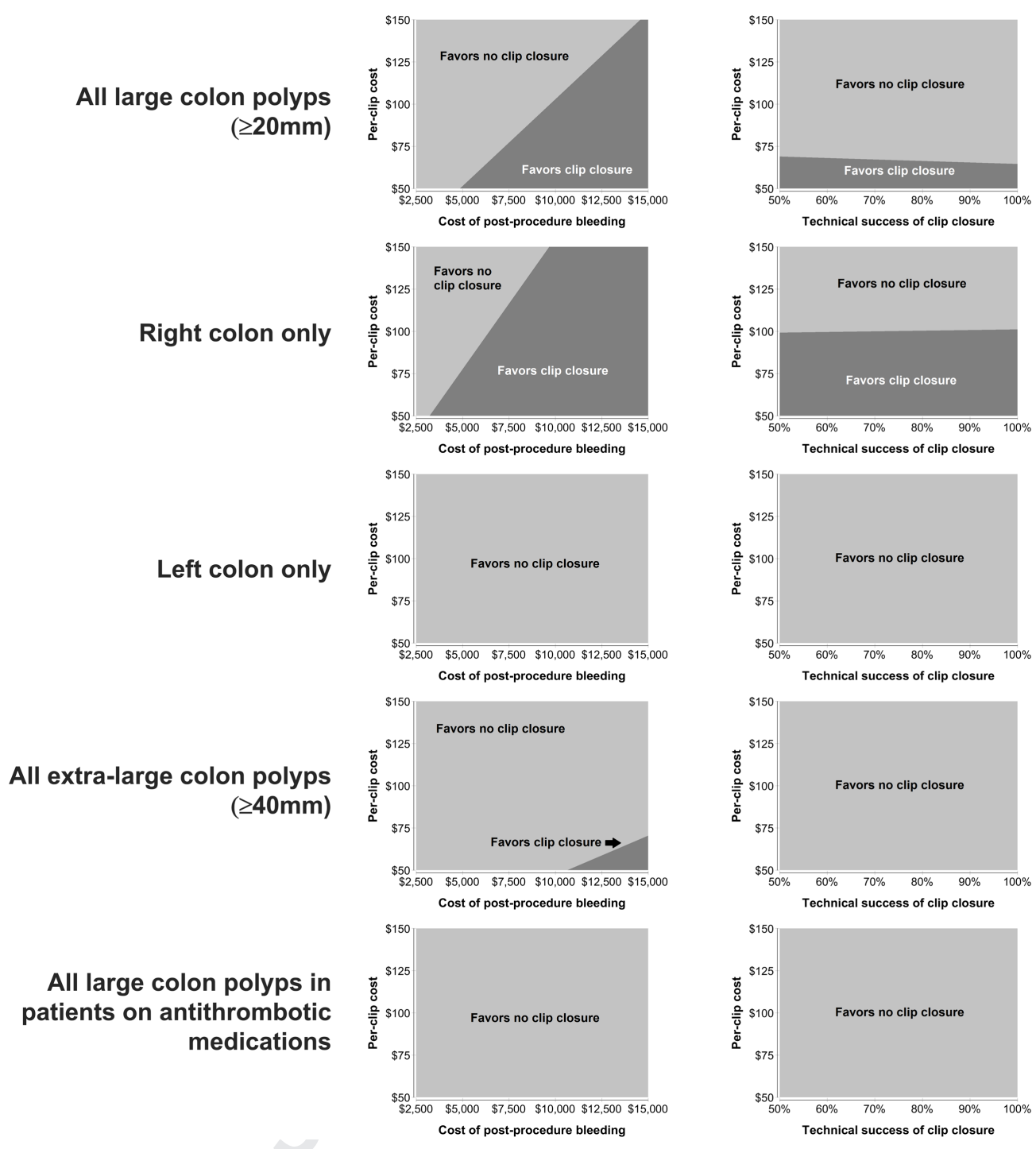




\section{ACRONYMS AND ABBREVIATIONS}

CI

CIN

CMS

EMR

$\mathrm{MC}$

MMC

OTS confidence interval

clinically integrated network

Centers for Medicare \& Medicaid Services

endoscopic mucosal resection

medical comorbidity

major medical comorbidity

over-the-scope 